Myers (instinct), Dr. W. H. Thorpe (learning processes in animals), Dr. F. B. Kirkman (bird behaviour), Prof. D. B. Johnstone-Wallace (grazing habits of beef cattle), and Dr. Arthur Walton (comparative sexual behaviour in the male). It was agreed also that Prof. Samson Wright and other psychiatrists should be invited to speak at this or a succeeding meeting. Future research projects were discussed, especially those in the veterinary field; for example, the individual behaviour of various domestic species, the grazing habits of sheep and cattle, and the utilization of behaviour reactions in supplementing clinical, pathological and biochemical studies of domestic mammals. Certain ornithological studies, suitable for members, were also discussed. It was decided to circulate these projects at an early date. Consideration was given to the matter of research grants, and it was agreed to take steps to try to secure funds for specific observational studies involving domestic animals. Membership of the Institute is open to all interested persons. The annual subscription (12s. 6d.) includes payment for the Bulletin of Animal Behaviour. Communications should be addressed to the Hon. Secretary, Institute for the Study of Animal Behaviour, c/o Zoological Society of London, Regent's Park, N.W.8.

\section{The War-time Social Survey}

A PAPER on the "War-time Social Survey" was read at a meeting of the Royal Statistical Society on May 16 by Kathleen Box and Geoffrey Thomas. The War-time Social Survey is the Government social research unit, and has been set up to provide any department with information, needed for the planning and administration of policy, which is not available from other sources. It is concerned with social problems, in the investigation of which it aims at establishing facts and attitudes of the public towards these facts. The method used to achieve these ends may be described briefly as interviewing samples of the general public, or of particular sections of the general public, with a recording schedule devised so that the results of the inquiries made can be expressed statistically. Investigations are carried out by fiftyfive trained fieldworkers, all women. The reception accorded to fieldworkers suggests that the public is ready to appreciate the importance of such inquiries and to give all possible help. The proportion of people eventually refusing to be interviewed is about 0.5 per cent in most inquiries. The Survey has had to rely very largely on devising its own techniques for different occasions as they arose. The experience gained by other workers in the field of social research, both in Great Britain and in the United States, has been used, and most members of the research staff, coming as they do from different organizations which have been doing allied work for many years, have had different contributions to make.

The Survey can provide a closer link between the administrator and administered than is normally possible, particularly in relation to the preparation and interpretation of departmental statistics. In each Department of State there has been a large amount of unco-ordinated statistics related to very limited aspects of the department's work. By the extension of the survey method such obstacles can be overcome. Thus the data which it is most convenient for a department to obtain by a return can be supplemented in many ways by sample inquiries and thus assist in making decisions of policy. In this way a most flexible instrument for the compilation of a wide range of statistics can be developed. At the same time each department can remain in close touch with the collection of data, since the Survey normally discusses an inquiry in great detail with the officers concerned before it goes into the field. The experience of the Survey has shown during the past two years that its work has satisfied a real need for a specialist body able to advise on aspects of social inquiry which go beyond the official return, and there is little reason to suppose that this need will disappear when the War comes to an end.

\section{Illuminating Engineering Society}

THE annual report for the past year of the Illuminating Engineering Society, presented at the annual meeting held on May 9, directs attention to the formation of new centres in Bath and Bristol, and new groups in Derby, Huddersfield and Stocktonon-Tees. The Society is now organizing its activities. through seven distinct areas, each with its own committee which in turn is represented on the areas joint committee. 243 new members have been added to the Society during the past year; the number of meetings held, upwards of sixty, exceeds that in pre-war days. Recent educational efforts include the organization of essay competitions for pupils in schools near Birmingham, and the giving of a series of Christmas lectures on "The Wonders of Lighting" to more than a thousand children in Bradford. The Society has been instrumental in forming a joint committee, with which leading physiologists are associated, to deal with the physiology of vision, and has completed, for the Ministry of War Transport, a special investigation into the brightness and legibility of traffic signs. Three of the series of illustrated lighting reconstruction pamphlets, dealing respectively with "Principles of Good Lighting", "The Lighting of Schools" and "The Lighting of Public Buildings" have recently been issued. The following officers have been elected for the present session : President, Mr. E. Stroud ; Hon. Treasurer, Mr. N. V. Everton; Hon. Secretary, Mr. J. S. Dow.

\section{Early Medical Books at Edinburgh}

To illustrate a current series of lectures by Dr. Douglas Guthrie on "The Historical Background to Modern Medicine", there has been placed on view a collection of early printed medical books in the Upper Library Hall of the University of Edinburgh. Founded in 1580 as a "Town's Library" three years before the foundation of the University, or "Town's College", the University Library remained the only public library in Edinburgh until the establishment of the Advocates' Library a hundred years later. Naturally it contains many treasures, including a number of works of medical interest from which the present selection has been made. The most important and valuable items in the exhibition are Vesalius's "De Corporis Humani Fabrica" and Harvey's "De Motu Cordis". The beautifully bound copy of the former is the first edition, from the press of Oporinus of Basel, 1543. Beside it lies the fine two-volume edition, printed at Leyden in 1725 by Boerhaave and Albinus. The first edition of Harvey's account of the circulation of the blood is now an extremely rare little book, dated from Frankfurt, 1628. Visitors to the exhibition will have the opportunity of seeing two perfect copies, one of which belonged to Alexander Monro, the third of the dynasty of professors 